\title{
Comparative Analysis of Abrasive Materials and Polishing System on the Surface Roughness of Heat-Polymerized Acrylic Resins
}

\author{
Stanley Chibuzor Onwubu ${ }^{1}$ Phumlane Selby Mdluli ${ }^{1}$ \\ ${ }^{1}$ Department of Chemistry, Durban University of Technology, \\ Address for correspondence Stanley Onwubu Chibuzor, PhD, \\ Durban, South Africa \\ Chemistry Department, Durban University of Technology, \\ Eur J Dent 2022;16:573-579. \\ Durban, South Africa (e-mail: StanleyO@dut.ac.za).
}

\begin{abstract}
Keywords

- abrasive materials

- eggshell powder

- polishing system

- pumice

- surface roughness

Objective The aim of this in vitro experiment was to see how the operator's manual skills, polishing equipment, and abrasive materials affected the surface roughness of denture base resins.

Materials and Methods Forty polymethyl methacrylate (PMMA) specimens were created and polished by using two different polishing systems, namely hand and automatic polishing machines. Three operators hand-polished 30 of specimens with eggshell powder and pumice, while 10 were automatically polished $(n=5)$. A profilometer was used to determine the average surface roughness $(\mathrm{Ra})$ after polishing. The Ra values for the specimens hand-polished were analyzed by using paired sample testing. The Ra values for all polished specimens were analyzed by using a one-way ANOVA. Differences between the two abrasive materials as well as the polishing system were determined by using the Bonferonni tests $(p=0.05)$.

Results and Conclusion For the PMMA specimens hand-polished, there was a strong connection in the Ra values. There were also significant variations in the Ra values across the three operators $(p<0.001)$. The automated technique created a substantially smoother surface than the traditional technique $(p=0.001)$. The greatest Ra values $(0.20 \mu \mathrm{m})$ were found in specimens polished traditionally by using pumice, whereas the lowest Ra values $(0.04 \mu \mathrm{m})$ were found in specimens polished mechanically with eggshell powder. The automated polishing system was the most effective polishing method when the Ra values were connected to the level of smoothness.
\end{abstract}

\section{Introduction}

For many years, acrylic resin made of polymethyl methacrylate (PMMA) has been the most popular denture base material due to its unique properties such as ease of processing, lightweight, cheap cost, aesthetic qualities, and stability in an oral environment. ${ }^{1,2}$ Despite this, the surface properties of PMMA denture base material are poor, ${ }^{3}$ which could subsequently act as a substrate for microorganism adherence and

published online December 10, 2021
DOI https://doi.org/

10.1055/s-0041-1736293. ISSN 1305-7456. biofilm formation. ${ }^{2}$ Since PMMA denture base materials are used in the oral cavity, a smooth and highly polished surface on an acrylic resin denture base is essential for maintaining dental health and preventing bacterial colonization. ${ }^{4,5}$ However, it is not apparent how best to get such a surface.

Tupinamba et $\mathrm{al}^{5}$ believe that correct polishing is essential in preventing bacterial retention and plaque build. Other investigations ${ }^{6-8}$ have found that the clinical quality and success of dental prostheses intraorally are determined by a

(c) 2021. The Author(s).

This is an open access article published by Thieme under the terms of the Creative Commons Attribution License, permitting unrestricted use, distribution, and reproduction so long as the original work is properly cited. (https://creativecommons.org/licenses/by/4.0/)

Thieme Medical and Scientific Publishers Pvt. Ltd., A-12, 2nd Floor, Sector 2, Noida-201301 UP, India 
well-polished and smooth denture surface. In addition, in vivo investigations ${ }^{9-11}$ have demonstrated that after polishing, the surface roughness of PMMA prosthesis should not exceed $0.2 \mu \mathrm{m}$.

PMMA dental prostheses hand-polished traditionally with pumice on a laboratory lathe machine create a surface roughness that surpasses the threshold value of $0.2 \mu \mathrm{m}$ according to some authors. ${ }^{12,13}$ Onwubu et $\mathrm{al}^{14}$ recently showed that eggshell powder with particle sizes ranging from 15 to $0.3 \mu \mathrm{m}$ may be employed as a substitute for pumice in reducing the surface roughness of PMMA base resin below the $0.2 \mu \mathrm{m}$ of threshold limit value. However, operator variability, according to Abuzar et al, ${ }^{15}$ can affect surface roughness values ( $\mathrm{Ra}$ ), which can lead to higher values in clinical practice. The goal of this in vitro experiment was to see how the operator's manual skills, polishing equipment, and abrasive materials affect the surface roughness of dental prostheses that were traditionally polished with eggshell powder and pumice using a laboratory lathe machine in comparison with those polished automatically.

The following hypotheses were tested: (1) there is variation in operator manual skills in decreasing the surface roughness of PMMA base resins; and (2) there is a significant difference in the abrasive materials employed and the surface roughness values measured (3) surface roughness values produced by the automatic polishing system significantly differs from the traditional laboratory lathe machine system.

\section{Materials and Methods}

Pumice (Navajo) was acquired from a local outlet in South Africa, and eggshell powder was created by using the process indicated by Onwubu et al. ${ }^{16-18}$ Sodium lauryl surfactant $(0.5 \mathrm{~g})$ was added to $20 \mathrm{~g}$ of blended eggshell powder to improve its wettability. The mixture was further milled following the procedure reported by Onwubu et al. ${ }^{16-18}$

\section{Scanning Electron Microscope}

A scanning electron microscope (S-3000N-Carl Zeiss) operating at controlled atmospheric conditions at $20 \mathrm{kV}$ was used to characterize the surface morphology of the eggshell powder and pumice. Before SEM observation, small quantities of the powders were spread in the sample holder and then coat sputtered for 30 minutes to prevent a build-up of electrostatic charge.

\section{Preparation of Polymethyl Methacrylate Specimens}

A total of $40(15 \times 15 \times 3 \mathrm{~mm})$ heat-polymerized acrylic resin specimens were created. All specimens were polymerized as per the manufacturer's instructions (Vertex-Dental BV). At $18,000 \mathrm{rpm}$, a tungsten carbide bur (Cross-cut, coarse - ISO no. 500104237065; Bredent GmbH \& Co KG) was used to trim the specimens. All specimens were completed with abrasive paper before polishing (CC768 Silicon Carbide; Deer Abrasives).

\section{Automatic and Conventional Polishing of the Polymethyl Methacrylate Specimens}

Three operators (skilled dental technicians) hand polished 30 specimens using a laboratory lathe machine at 1,500 rpm for 2 minutes each $(n=5)$, with eggshells and pumice as the two abrasive materials (-Table 1). The water and powder consistency was achieved by mixing $30 \mathrm{~g}$ of powder with $5 \mathrm{~mL}$ of water to form a slurry. On the other hand, 10 specimens were automatically polished $(n=5)$. The specimens were inserted in a mounting resin prior to automatic polishing (AMT composite). A silicone rubber mold was used as the mounting foundation for the specimens during the embedding preparation. PMMA specimens were then inserted into the mold. Part A and Part B (Composite) were mixed in a disposable plastic cup to make a fast-setting resin, which was then poured into the mold in a 1:1 ratio. The embedded resin was removed from the silicone mold after 2 minutes. The procedure and process of automatic polishing are detailed in Onwubu et al. ${ }^{4}$

\section{Surface Roughness Analysis}

Using a Wintrace surface analysis system profilometer, the surface roughness (Ra values) of PMMA specimens was measured (Taylor Hobson Ltd). A 0.8-mm cut-off filter, a $4.00-\mathrm{mm}$ evaluation length, and a range of $5.1 \mu \mathrm{m}$ were used to calibrate the profilometer. Each specimen had five measures of surface roughness, and the statistical analysis was based on the mean average Ra values.

\section{Statistical Analysis}

The Shapiro-Wilk test was done to evaluate the normality of the Ra values by using software (SPSS v27; IBM Corp). The paired sample test was used to examine the intragroup mean differences of the polished PMMA specimens polished manually by various operators, while the independent sample

Table 1 Polishing process and sample size

\begin{tabular}{|c|c|c|c|c|c|}
\hline Operator(s) & Polishing materials & Polishing system & $\begin{array}{l}\text { Number of } \\
\text { specimens }\end{array}$ & $\begin{array}{l}\text { Revolution } \\
\text { per minute }\end{array}$ & Time (min) \\
\hline Operator 1 & \multirow[t]{4}{*}{ Eggshells and pumice } & \multirow[t]{3}{*}{ Laboratory lathe (RENO) } & 10 & 1,500 & 2 \\
\hline Operator 2 & & & 10 & 1,500 & 2 \\
\hline Operator 3 & & & 10 & 1,500 & 2 \\
\hline Automatic machine & & RotoPol-35, PdM-Force-20; Struers & 10 & 300 & 2 \\
\hline
\end{tabular}



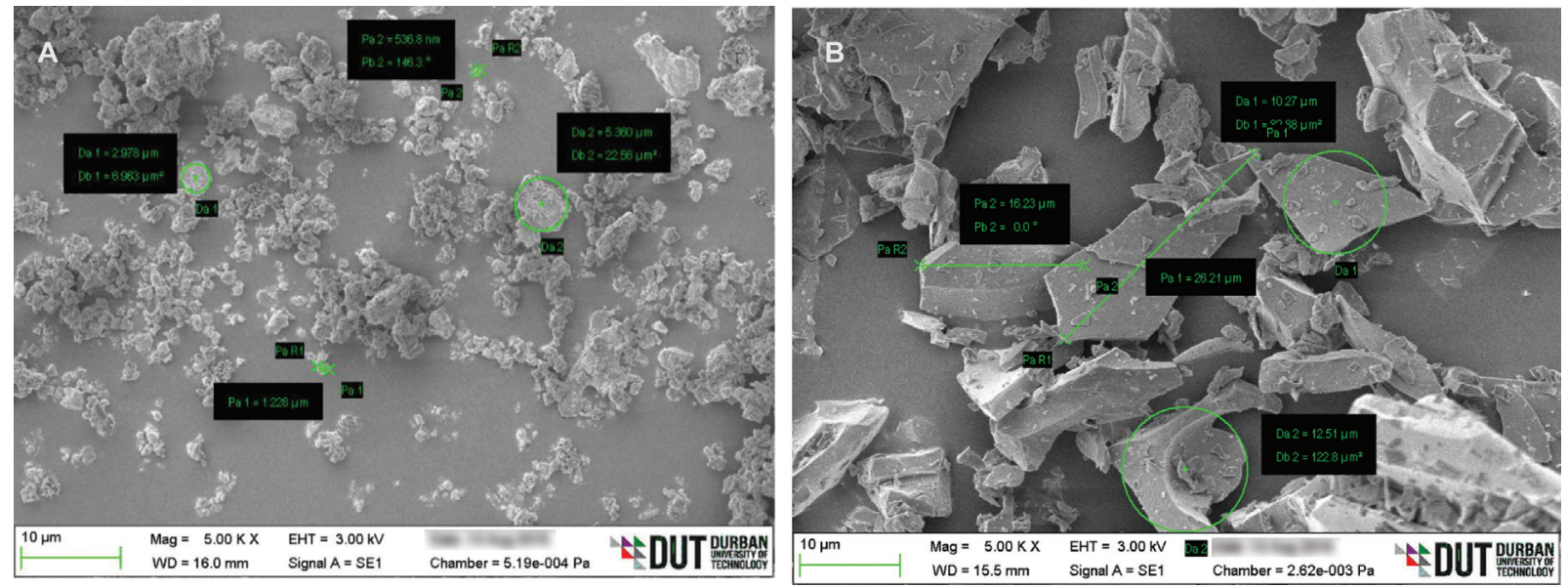

Fig. 1 Scanning electron microscope images showing (A) eggshell powder, and (B) pumice showing particle.

test was utilized to evaluate the intergroup mean differences of the polished PMMA specimens. To compare the polished surfaces of the PMMA specimens in the automated polished group, a one-way analysis of variance (ANOVA) was employed, which followed by the Bonferroni test $(\alpha=0.05)$.

\section{Results}

\section{Surface Morphology of Eggshell Powder and Pumice}

The eggshell powder particles have an irregular form and a sponge-like structure, as seen by the SEM image ( - Fig. 1A). The image reveals that the eggshell powder had uneven particle size distribution in a range of 1.9 to $568 \mathrm{~nm}$. O'Brien ${ }^{19}$ believes that this uneven particle form is beneficial in creating better-polished surfaces. On the contrary, the SEM image for pumice reveals triangular like particles (-Fig. 1B). The particle distribution for pumice reveals an uneven distribution in a range of 10 to $26 \mu \mathrm{m}$.

\section{Operator's Manual Skills Analysis}

The normal distributions of the operator's manual skills on the $R_{a}$ values of the polished specimens are presented in -Table 2. The Shapiro-Wilk test for normality showed no significant differences against the normality of the $R_{a}$ values $(p>0.05)$.

The paired sample test for the intra-mean comparison results is illustrated in - Table 3 . A positive strong correlation
Table 2 Normality test

\begin{tabular}{|l|l|l|l|l|}
\hline Operators & Type of & \multicolumn{3}{|l|}{ Shapiro-Wilk test } \\
\cline { 3 - 5 } & $\begin{array}{l}\text { abrasive } \\
\text { material }\end{array}$ & $d f$ & $p$-Value & $\begin{array}{l}\text { Level of } \\
\text { significance }\end{array}$ \\
\hline Operator 1 & $\begin{array}{l}\text { Eggshell } \\
\text { powder }\end{array}$ & 5 & 0.754 & Not significant \\
\cline { 2 - 5 } & Pumice & 5 & 0.141 & Not significant \\
\hline Operator 2 & $\begin{array}{l}\text { Eggshell } \\
\text { powder }\end{array}$ & 5 & 0.135 & Not significant \\
\cline { 2 - 5 } & Pumice & 5 & 0.272 & Not significant \\
\hline Operator 3 & $\begin{array}{l}\text { Eggshell } \\
\text { powder }\end{array}$ & 5 & 0.814 & Not significant \\
\cline { 2 - 5 } & Pumice & 5 & 0.215 & Not significant \\
\hline
\end{tabular}

was found in the surface roughness for the PMMA specimens polished manually by the different operators. An examination of the $R_{a}$ values means for operator 1 and operator 2 for example (combined pumice and eggshell powder) indicates that the $R_{a}$ values of operator $2(0.10 \pm 0.06 \mu \mathrm{m})$ were significantly higher than the operator $1(0.15 \pm 0.06 \mu \mathrm{m})$. Similar pattern is observed for operator $3(0.13 \pm 0.07 \mu \mathrm{m})$ and operator $1 \quad(0.15 \pm 0.06 \mu \mathrm{m})$, as well as operator $2(0.10 \pm 0.06 \mu \mathrm{m})$ and operator $3(0.13 \pm 0.07 \mu \mathrm{m})$.

Table 3 Intragroup mean comparison

\begin{tabular}{|l|l|l|l|l|l|l|l|}
\hline \multicolumn{2}{|l|}{ Operators } & Mean & $n$ & \pm SD & \pm SE & Correlation & $p$-Value \\
\hline \multirow{3}{*}{ Pair 1 } & Operator 1 & 0.15 & 10 & 0.06 & 0.02 & 0.866 & \multirow{2}{*}{0.001} \\
\cline { 2 - 6 } & Operator 2 & 0.10 & 10 & 0.06 & 0.02 & & \\
\hline \multirow{3}{*}{ Pair 2 } & Operator 1 & 0.15 & 10 & 0.06 & 0.02 & 0.926 & \multirow{2}{*}{0.000} \\
\cline { 2 - 6 } & Operator 3 & 0.13 & 10 & 0.07 & 0.02 & & \\
\cline { 1 - 6 } Pair 3 & Operator 2 & 0.10 & 10 & 0.06 & 0.02 & 0.831 & \multirow{2}{*}{0.003} \\
\cline { 2 - 5 } & Operator 3 & 0.13 & 10 & 0.07 & 0.02 & & \\
\hline
\end{tabular}

Abbreviations: SD, standard deviation; SE, standard error. 
Table 4 Intergroup mean comparison

\begin{tabular}{|c|c|c|c|c|c|c|c|}
\hline \multicolumn{2}{|c|}{ Type of Abrasive material } & $n$ & Mean & $\pm \mathrm{SD}$ & $\pm \mathrm{SE}$ & $p$-Value & Significance \\
\hline \multirow[t]{2}{*}{ Operator 1} & Eggshell powder & 5 & 0.0940 & 0.02074 & 0.00927 & \multirow[t]{2}{*}{0.000} & \multirow[t]{2}{*}{ Significance } \\
\hline & Pumice & 5 & 0.2020 & 0.02950 & 0.01319 & & \\
\hline \multirow[t]{2}{*}{ Operator 2} & Eggshell powder & 5 & 0.0520 & 0.01095 & 0.00490 & \multirow[t]{2}{*}{0.000} & \multirow[t]{2}{*}{ Significance } \\
\hline & Pumice & 5 & 0.1520 & 0.02168 & 0.00970 & & \\
\hline \multirow[t]{2}{*}{ Operator 3} & Eggshell powder & 5 & 0.0660 & 0.01140 & 0.00510 & \multirow[t]{2}{*}{0.001} & \multirow[t]{2}{*}{ Significance } \\
\hline & Pumice & 5 & 0.1880 & 0.03493 & 0.01562 & & \\
\hline
\end{tabular}

Abbreviations: SD, standard deviation; SE, standard error.

The intergroup mean comparison of PMMA specimens polished with different polishing materials by various operators is shown in -Table 4. Overall, the Ra values of the eggshell powder-polished specimens were substantially lower than those of the pumice-polished specimens $(p<0.001)$.

After 2 minutes of polishing, differences in mean surface roughness ( $\mathrm{Ra}$ ) of PMMA specimens hand-polished with eggshell powder and pumice abrasive materials by 3 separate operators ( $\mathrm{n}=5$; - Fig. 2). PMMA stands for polymethylmethacrylate (methyl methacrylate).

\section{Automatic Versus Conventional Polishing Analysis}

- Table 5 illustrates the $R_{a}$ values obtained from the profilometry analysis of the PMMA specimens that were automatically and manually polished. As revealed by the $R_{a}$ values, uniformity and consistency in the polishing were observed for the specimens that were automatically polished with pumice and eggshell powder. In contrast, inconsistencies were observed in the $\mathrm{R}_{\mathrm{a}}$ values, particularly in respect to the PMMA specimens conventionally polished with pumice.

- Table 6 shows the 1-way ANOVA, mean, standard deviation, and standard error data. Surface roughness for PMMA specimens and their interactions with abrasive materials, as well as the polishing method employed in the polishing process, were found to be significantly different $(p<0.001)$.

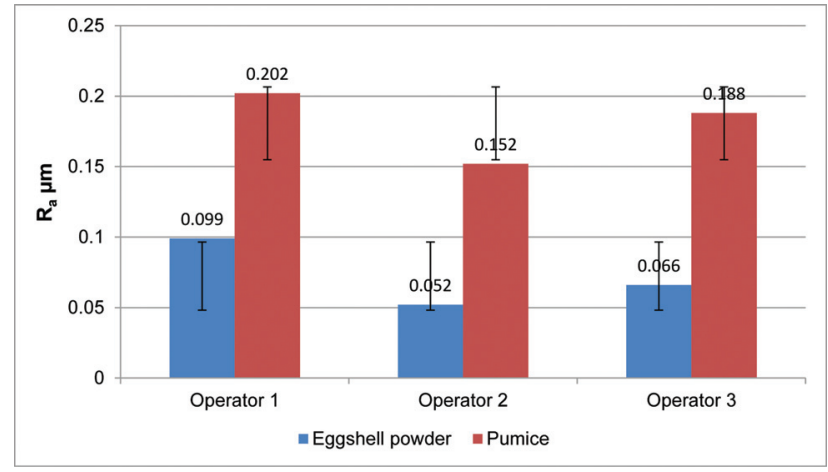

Fig. 2 This shows the variations in the mean value of surface roughness received from the operator using various polishing products.

When it came to the polishing system, the group that was automatically polished with pumice had the lowest Ra mean $(0.06 \pm 0.00 \mu \mathrm{m})$ compared to the PMMA specimens that were hand-polished. Similarly, the group that polished with eggshell powder automatically had the lowest Ra mean value $(0.04 \pm 0.00 \mu \mathrm{m})$. The Ra values of the group polished with pumice were substantially lower than the Ra values of the specimens hand-polished conventionally by operators 1,2 , and $3(p<0.001)$.

Table 5 The surface roughness value of polymethyl methacrylate specimens polished with eggshell powder

\begin{tabular}{|c|c|c|c|c|c|}
\hline & \multirow[t]{2}{*}{$\mathrm{S} / \mathrm{N}$} & \multicolumn{3}{|c|}{$\begin{array}{l}\text { Conventional polishing system } \\
\left(R_{\mathrm{a}} \mu \mathrm{m}\right)\end{array}$} & \multirow[t]{2}{*}{$\begin{array}{l}\text { Automatic polishing system } \\
\left(R_{a} \mu m\right)\end{array}$} \\
\hline & & Operator 1 & Operator 2 & Operator 3 & \\
\hline \multirow[t]{5}{*}{ Eggshell powder } & 1 & 0.12 & 0.07 & 0.06 & 0.03 \\
\hline & 2 & 0.08 & 0.05 & 0.05 & 0.05 \\
\hline & 3 & 0.09 & 0.05 & 0.08 & 0.04 \\
\hline & 4 & 0.11 & 0.04 & 0.07 & 0.03 \\
\hline & 5 & 0.07 & 0.05 & 0.07 & 0.04 \\
\hline \multirow[t]{5}{*}{ Pumice } & 1 & 0.25 & 0.13 & 0.22 & 0.06 \\
\hline & 2 & 0.19 & 0.14 & 0.21 & 0.06 \\
\hline & 3 & 0.18 & 0.17 & 0.13 & 0.06 \\
\hline & 4 & 0.21 & 0.18 & 0.19 & 0.05 \\
\hline & 5 & 0.18 & 0.14 & 0.19 & 0.06 \\
\hline
\end{tabular}


Table 6 The ANOVA test for abrasive material and polishing system

\begin{tabular}{|c|c|c|c|c|c|c|c|c|}
\hline \multirow{2}{*}{\multicolumn{2}{|c|}{\begin{tabular}{|l|} 
\\
Polishing material and system
\end{tabular}}} & \multirow[t]{2}{*}{$n$} & \multirow[t]{2}{*}{ Mean } & \multirow[t]{2}{*}{$\pm \mathrm{SD}$} & \multicolumn{2}{|c|}{$95 \% \mathrm{Cl}$ for mean } & \multirow{2}{*}{$\frac{\text { ANOVA test }}{p \text {-Value }}$} & \multirow[t]{2}{*}{ Bonferroni test } \\
\hline & & & & & Lower bound & Upper bound & & \\
\hline \multirow{4}{*}{$\begin{array}{l}\text { Polished with eggshell } \\
\text { powder }\end{array}$} & Operator $^{\mathrm{a}} 1$ & 5 & 0.09 & 0.02 & 0.0683 & 0.1197 & \multirow[t]{4}{*}{0.000} & $0.000^{\mathrm{a}, \mathrm{d}}$ \\
\hline & Operator $^{\mathrm{b}} 2$ & 5 & 0.05 & 0.01 & 0.0384 & 0.0656 & & $0.000^{\mathrm{a}, \mathrm{d}}$ \\
\hline & Operator $^{\mathrm{c}} 3$ & 5 & 0.07 & 0.01 & 0.0518 & 0.0802 & & $0.000^{\mathrm{a}, \mathrm{d}}$ \\
\hline & Automatic $^{d}$ & 5 & 0.04 & 0.00 & 0.0276 & 0.0484 & & \\
\hline \multirow[t]{4}{*}{ Polished with pumice } & Operator $^{\mathrm{a}} 1$ & 5 & 0.20 & 0.03 & 0.1654 & 0.2386 & \multirow[t]{4}{*}{0.000} & $0.000^{\mathrm{a}, \mathrm{d}}$ \\
\hline & Operator $^{\mathrm{b}} 2$ & 5 & 0.15 & 0.02 & 0.1251 & 0.1789 & & $0.753^{b, d}$ \\
\hline & Operator $^{\mathrm{C}} 3$ & 5 & 0.19 & 0.03 & 0.1446 & 0.2314 & & $0.031^{c, d}$ \\
\hline & Automatic $^{d}$ & 5 & 0.06 & 0.00 & 0.0524 & 0.0636 & & \\
\hline
\end{tabular}

Abbreviations: ANOVA, analysis of variance; $\mathrm{Cl}$, confidence interval; SD, standard deviation; SE, standard error.

a Operator 1

'Operator 2

'Operator 3

${ }^{\mathrm{d}}$ Automatic

The Ra values of the specimens hand-polished traditionally by operators 1 and 3 were substantially lower than those of the group polished automatically using eggshell powder $(p<0.001)$. The Ra values of the group polished automatically with eggshell powder and operator 2 did not differ significantly $(p>0.05)$. Overall, the group that operator 1 hand-polished with pumice had the greatest Ra mean value $(0.2 \pm 0.03 \mu \mathrm{m})$, whereas the group that was automatically polished with eggshell powder had the lowest Ra mean value $(0.04 \pm 0.01 \mu \mathrm{m})$.

\section{Discussion}

Previous studies reveal the surface roughness of PMMA resins is influenced by the material's intrinsic properties, the polishing method, and the operator's physical abilities. ${ }^{20,21}$ Tupinamba et $\mathrm{al}^{5}$ note that polishing is a surface treatment that involves the use of appropriate materials and processes. Dental prostheses are traditionally hand-polished in the dental laboratory by using a lathe machine and pumice as the abrasive material. ${ }^{22}$ Despite this, Corsalini et $\mathrm{al}^{20}$ argued for the adoption of an automated polishing system instead of the traditional polishing approach. The influence of operator manual skills, polishing method, and abrasive materials on the surface roughness of dental prostheses was compared in this study. The surface roughness of the PMMA resins was measured by using profilometry with a contacting stylus. The roughness parameter ( $\mathrm{Ra}$ ) was measured, and statistical analysis was performed. The Ra value which corresponds to the average peak and valley distance is an important parameter commonly used to quantitatively describe the surface roughness in vitro. ${ }^{14,23}$ Although the Ra does not measure the amplitude and spacing of superficial irregularities, ${ }^{23}$ nevertheless, the surface roughness of a PMMA denture base resin is clinically benchmarked using the Ra values. ${ }^{24}$

Moreover, and in light of the several clinical studies on surface roughness reported in the literature, ${ }^{9,10}$ the results obtained in this study were explained by using the Ra threshold value of $0.2 \mu \mathrm{m}$. The first hypothesis was accepted based on the study results. The intragroup data (-Table 2) demonstrated that there was significant variability in the operators and the surface roughness $\left(R_{a}\right)$ value of the polished PMMA specimens $(p<0.01)$. The differences in the surface roughness value obtained from the three operators could be attributed to the inconsistency in hand polishing a denture. ${ }^{15,20}$ Corsalini et al $^{20}$ noted that the operator's hand abilities are influenced by human variables such as attentiveness and writs trembling, which can affect the surface finish quality. The aforementioned factors could have had an impact on the measured differences in surface roughness.

Overall, the Ra values recorded in all of the PMMA groups hand-polished with eggshell powder were considerably lower than those observed in the pumice-polished specimens ( $p<0.001$ ), which led to the acceptance of the second hypothesis. From a clinical perspective, and consistent with Onwubu et $\mathrm{al}^{14}{ }^{14}$ the lower $\mathrm{R}_{\mathrm{a}}$ values measured with eggshell powder suggest that the abrasive material is more likely to produce a more highly polished dental prosthesis. More so, the different $R_{a}$ values between the eggshell powder and pumice may be related to the differences in the particle sizes between the two abrasive materials ( - Fig. 1), which reveal that eggshell power had smaller particle sizes when compared to pumice. It is reported that abrasive materials of smaller particle sizes created newly formed and sharper particles faster during the abrasion process, which in turn reduces the surface roughness of dental prostheses. ${ }^{25}$ Also, the inclusion of surfactant in eggshell powder could have contributed to the differences in the $R_{a}$ values between eggshell powder and pumice. Surface-active compounds such as surfactants have been reported to improve the wettability and to enhance the mechanical properties of materials. ${ }^{26,27}$

Moreover, the findings of this study demonstrated that an automatic polishing method is more likely than manual polishing to provide a better polished (-Table 6 ). The 
PMMA group with the highest mean average was handpolished with pumice by operator $1(0.20 \pm 0.03 \mu \mathrm{m})$, whereas the lowest was automatically polished with eggshell powder $(0.04 \pm 0.01 \mu \mathrm{m})$. This could, however, be attributed to the standardization of the polishing process, which minimizes the human factors consistent with hand polishing. ${ }^{4,20}$ As a consequence, the third hypothesis was accepted, as the polishing systems used in this study were significantly different in respect to the surface roughness values $(p<0.01)$.

Furthermore, the findings of this investigation, particularly the hand-polished PMMA specimen, are consistent with those of Srividya et al $^{13}$ and Onwubu et al. ${ }^{14}$ They reported a mean Ra value of 0.36 to $0.13 \mu \mathrm{m}$, which matches the findings of this study. However, Kuhar and Funduk ${ }^{28}$ reported a Ra value of $0.79 \mu \mathrm{m}$. It is worth noting that Al-Kheraif, ${ }^{29}$ who employed a pumice-automated polishing method, obtained results that are comparable to the average Ra values obtained in this study's pumice-automated polishing group. Furthermore, Onwubu et $\mathrm{al}^{14}$ observed a mean Ra value of $0.07 \mu \mathrm{m}$ on PMMA specimens hand-polished with eggshell powder (fine $=0.5 \mu \mathrm{m}$ ), which matches the findings of our investigation.

Although the automatic polishing system produced useful and reliable findings in our investigation, it has certain drawbacks. Appliances are created to fit the mouths of individual patients at a dental laboratory. As a result, an automated polishing system cannot be used since denture polishing is never done on entirely level surfaces. To establish the efficiency of the automated polishing system on the surface roughness of dentures made for dental patients, more clinical investigations are needed.

\section{Conclusion}

Within the limitations of the present in vitro study, it can be concluded that the most efficient polishing technology for minimizing the surface roughness of PMMA base resins is automatic polishing. The eggshell powder may be utilized as an alternate abrasive material in hand and automatic polishing of denture base materials. From a dental laboratory perspective, this study is highly useful to dental technicians in the selection of abrasive materials as well as the choice of the polishing system that could produce clinically acceptable PMMA dentures.

\section{Funding}

The authors acknowledged the financial support from the National Research Foundation of South Africa (grant no. 129492).

\section{Conflict of Interest}

None declared.

\section{References}

1 Sakaguchi RL, Powers JM. Craig's restorative dental materials-ebook. Elsevier Health Sciences; 2012
2 An S, Evans JL, Hamlet S, Love RM. Incorporation of antimicrobial agents in denture base resin: a systematic review. J Prosthet Dent 2020:1-10

3 Murakami N, Wakabayashi N, Matsushima R, Kishida A, Igarashi Y. Effect of high-pressure polymerization on mechanical properties of PMMA denture base resin. J Mech Behav Biomed Mater 2013; 20:98-104

4 Onwubu SC, Mdluli PS, Singh S. The effect of colloidal silica and diamond suspensions on the surface roughness of automatically finished heat-polymerized acrylic resin. J Prosthet Dent 2018;120 (03):485.e1-485.e5

5 Tupinambá ÍVM, Giampá PCC, Rocha IAR, Lima EMCX. Effect of different polishing methods on surface roughness of provisional prosthetic materials. J Indian Prosthodont Soc 2018;18(02):96-101

6 Gungor H, Gundogdu M, Yesil Duymus Z. Investigation of the effect of different polishing techniques on the surface roughness of denture base and repair materials. J Prosthet Dent 2014;112 (05):1271-1277

7 Rao DC, Kalavathy N, Mohammad HS, Hariprasad A, Kumar CR. Evaluation of the surface roughness of three heat-cured acrylic denture base resins with different conventional lathe polishing techniques: A comparative study. J Indian Prosthodont Soc 2015; 15(04):374-380

8 Sadeghi M, Deljoo Z, Bagheri R. The influence of surface polish and beverages on the roughness of nanohybrid and microhybri resin composite. J Dent Biomater 2016;3(01):177-185

9 Bollen CM, Lambrechts P, Quirynen M. Comparison of surface roughness of oral hard materials to the threshold surface roughness for bacterial plaque retention: a review of the literature. Dent Mater 1997;13(04):258-269

10 Kim SK, Park JM, Lee MH, Jung JY, Li S, Wang X. Effects of chairside polishing and brushing on surface roughness of acrylic denture base resins. J Wuhan University Technol Mater Sci Ed 2009;24 (01):100-105

11 Marchan S, Bishop A, Smith W, Seerattan P, Hinds D. A comparative assessment of the surface roughness of thermoplastic denture base resins following adjustment and re-polishing. Open J Stomatol 2017;7(04):250-263

12 Berger JC, Driscoll CF, Romberg E, Luo Q Thompson G. Surface roughness of denture base acrylic resins after processing and after polishing. J Prosthodont 2006;15(03):180-186

13 Srividya S, Nair CK, Shetty J. Effect of different polishing agents on surface finish and hardness of denture base acrylic resins: a comparative study. Int J Prosthodont Restor Dent 2011;1(01): 7-11

14 Onwubu SC, Vahed A, Singh S, Kanny KM. Reducing the surface roughness of dental acrylic resins by using an eggshell abrasive material. J Prosthet Dent 2017;117(02):310-314

15 Abuzar MA, Bellur S, Duong N, et al. Evaluating surface roughness of a polyamide denture base material in comparison with poly (methyl methacrylate). J Oral Sci 2010;52(04):577-581

16 Onwubu SC, Vahed A, Singh S, Kanny KM. Physicochemical characterization of a dental eggshell powder abrasive material. J Appl Biomater Funct Mater 2017;15(04):e341-e346

17 Onwubu SC, Mdluli PS, Singh S, Bharuth V, Makgobole MU. Evaluation of the occluding characteristics of nanosized eggshell/titanium dioxide with or without saliva. Eur J Dent 2019;13(04):547-555

18 Onwubu SC, Mdluli PS, Singh S, Bharuth V. Remineralization potential of a modified eggshell-titanium composite-scanning electron microscope Study. Eur J Dent 2019;13(02):187-192

19 O'Brien WJ. Dental Materials and Their Selection: Abrasion, Polishing, and Bleaching. 3rd ed. Chicago: Quintessence Publishing Co, Inc.; 2002

20 Corsalini M, Boccaccio A, Lamberti L, Pappalettere C, Catapano S, Carossa S. Analysis of the performance of a standardized method for the polishing of methacrylic resins. Open Dent J 2009;3:233-240 
21 Mekkawy MA, Hussein LA, Alsharawy MA. Comparative study of surface roughness between polyamide, thermoplastic polymethyl methacrylate and acetal resins flexible denture base materials before and after polishing. Life Sci J 2015;12(10): 90-95

22 Al-Rifaiy MQ. The effect of mechanical and chemical polishing techniques on the surface roughness of denture base acrylic resins. Saudi Dent J 2010;22(01):13-17

23 Tosco V, Monterubbianesi R, Orilisi G, et al. Effect of four different finishing and polishing systems on resin composites: roughness surface and gloss retention evaluations. Minerva Stomatol 2020; 69(04):207-214

24 Jones CS, Billington RW, Pearson GJ. The in vivo perception of roughness of restorations. Br Dent J 2004;196(01):42-45, discussion 31
25 Hanna BA, Abd Al-Majeed AE, AbdulRazaak W. Effect of different dental materials on the surface roughness of acrylic resin (A comparative in vitro study). MDJ 2008;5:281-285

26 Song EM, Kim DW, Lim JC. Effect of adsorption of laureth sulfonic acid type anionic surfactant on the wetting property of $\mathrm{CaCO} 3$ substrate. J Ind Eng Chem 2015;28:351-358

27 Song E, Kim D, Kim BJ, Lim J. Surface modification of $\mathrm{CaCO} 3$ nanoparticles by alkylbenzene sulfonic acid surfactant. Colloids Surf A Physicochem Eng Asp 2014;461:1-10

28 Kuhar M, Funduk N. Effects of polishing techniques on the surface roughness of acrylic denture base resins. J Prosthet Dent 2005;93 (01):76-85

29 Al-Kheraif AA AThe effect of mechanical and chemical polishing techniques on the surface roughness of heat-polymerized and visible lightpolymerized acrylic denture base resins. Saudi Dent J 2014;26(02):56-62 